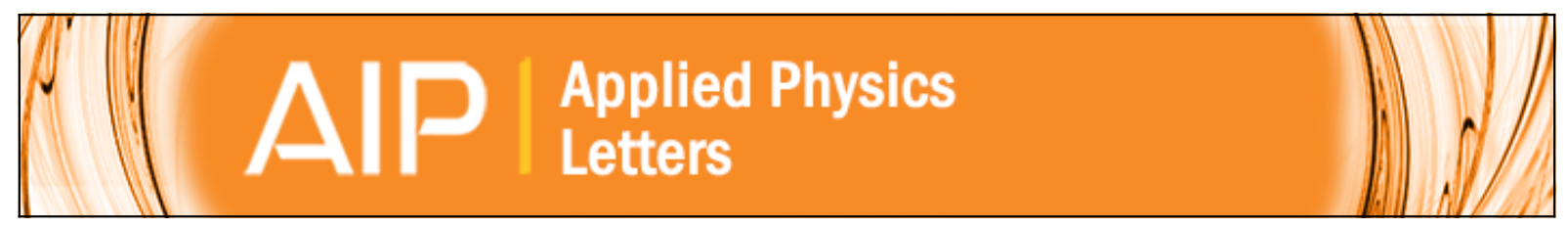

\title{
Cathodoluminescence depth profiling of ion-implanted GaN
}

S. O. Kucheyev, M. Toth, M. R. Phillips, J. S. Williams, C. Jagadish, and G. Li

Citation: Applied Physics Letters 78, 34 (2001); doi: 10.1063/1.1337646

View online: http://dx.doi.org/10.1063/1.1337646

View Table of Contents: http://scitation.aip.org/content/aip/journal/apl/78/1?ver=pdfcov

Published by the AIP Publishing

\section{Articles you may be interested in}

Europium doping of zincblende $\mathrm{GaN}$ by ion implantation

J. Appl. Phys. 105, 113507 (2009); 10.1063/1.3138806

Magnesium/nitrogen and beryllium/nitrogen coimplantation into $\mathrm{GaN}$

J. Appl. Phys. 98, 073702 (2005); 10.1063/1.2073969

Blueshift of yellow luminescence band in self-ion-implanted n- GaN nanowire

Appl. Phys. Lett. 84, 3486 (2004); 10.1063/1.1738172

Enhanced dynamic annealing in $\mathrm{Ga}+$ ion-implanted $\mathrm{GaN}$ nanowires

Appl. Phys. Lett. 82, 451 (2003); 10.1063/1.1536250

Photo-, cathodo-, and electroluminescence from erbium and oxygen co-implanted GaN

J. Appl. Phys. 81, 6343 (1997); 10.1063/1.364369

\section{Model PS-100}

Tabletop Cryogenic Probe Station

\section{Lake Shore} CRYOTRONICS

\author{
An affordable solution for
} a wide range of research 


\title{
Cathodoluminescence depth profiling of ion-implanted GaN
}

\author{
S. O. Kucheyeva) \\ Department of Electronic Materials Engineering, Research School of Physical Sciences and Engineering, \\ The Australian National University, Canberra, ACT 0200, Australia \\ M. Toth ${ }^{\text {b) }}$ and M. R. Phillips \\ Microstructural Analysis Unit, University of Technology, Sydney, Broadway, NSW 2007, Australia
}

J. S. Williams and C. Jagadish

Department of Electronic Materials Engineering, Research School of Physical Sciences and Engineering, The Australian National University, Canberra, ACT 0200, Australia

G. Li

Ledex Corporation, No. 9, Ta-Yio First Street, Ta-Fa Industrial District, Kaohsiung County, Taiwan, Republic of China

(Received 25 September 2000; accepted for publication 2 November 2000)

\begin{abstract}
Cathodoluminescence (CL) spectroscopy shows that even relatively low-dose keV light-ion bombardment (corresponding to the generation of $\sim 5 \times 10^{19}$ vacancies $/ \mathrm{cm}^{3}$ ) of wurtzite $\mathrm{GaN}$ results in a dramatic quenching of visible CL emission. Postimplantation annealing at temperatures up to $1050{ }^{\circ} \mathrm{C}$ generally causes a partial recovery of measured CL intensities. However, CL depth profiles indicate that, in most cases, such a recovery results from CL emission from virgin GaN, beyond the implanted layer due to a reduction in the extent of light absorption within the implanted layer. In this case, CL emission from the implanted layer remains completely quenched even after such an annealing. These results show that an understanding of the effects of ion bombardment and postimplantation annealing on luminescence generation and light absorption is required for a correct interpretation of luminescence spectra of $\mathrm{GaN}$ optically doped by $\mathrm{keV}$ ion implantation. (C) 2001 American Institute of Physics. [DOI: 10.1063/1.1337646]
\end{abstract}

The technological importance of GaN has stimulated a considerable research effort to understand the properties of this material. ${ }^{1}$ In particular, the luminescence properties of GaN have received extensive attention due to their importance in the fabrication of GaN-based optoelectronic devices.

One way to modify the optical properties of $\mathrm{GaN}$ is by the introduction of optically active impurities (such as rareearth elements) by ion implantation. However, ion implantation inevitably produces lattice disorder which is well known to have a detrimental effect on the luminescence of $\mathrm{GaN}$ in the visible part of the spectrum. Implantation-produced lattice defects act as nonradiative recombination centers in $\mathrm{GaN}$, resulting in a severe quenching of most characteristic luminescence peaks exhibited by as-grown $\mathrm{GaN}$ (see, for example, Refs. 2-7). Partial elimination of such ion-beaminduced luminescence quenching by postimplantation annealing has been reported by several groups and is generally attributed to a corresponding partial recovery of nonradiative defects produced by ion bombardment. ${ }^{2-6}$ In this letter, we present cathodoluminescence (CL) data which indicate that implantation-produced damage and postimplantation annealing affect not only light emission from the implanted layer but also the detection of CL emission from virgin $\mathrm{GaN}$ due to the absorption of light within the implanted layer. Awareness of this behavior is required for a correct interpretation of

\footnotetext{
a) Author to whom correspondence should be addressed; electronic mail: sok109@rsphysse.anu.edu.au

b) Present address: Polymers and Colloids Group, Cavendish Laboratory, University of Cambridge, Madingley Rd., Cambridge CB3 OHE, UK.
}

luminescence measurements of GaN optically doped by implantation with $\mathrm{keV}$ ions.

The samples used in this study were cut from three wafers of $\sim 2 \mu \mathrm{m}$ thick nominally undoped wurtzite GaN epilayers grown on $c$-plane sapphire substrates by metalorganic chemical vapor deposition in three different EMCORE reactors. The samples were implanted with $\mathrm{keV}{ }^{1} \mathrm{H},{ }^{12} \mathrm{C},{ }^{14} \mathrm{~N}$, or ${ }^{16} \mathrm{O}$ ions. Qualitatively, the results discussed in this letter are representative of all implanted samples. For brevity, we will only present data obtained using the samples cut from one of the three $\mathrm{GaN}$ wafers and implanted with $\mathrm{C}$ ions. Implantation with $150 \mathrm{keV}{ }^{12} \mathrm{C}^{-}$ions was done at room temperature (RT) or liquid nitrogen temperature $\left(\mathrm{LN}_{2}\right)$ over a wide dose range using the ANU $180 \mathrm{kV}$ ion implanter. During implantation, each sample was partly masked by a piece of $\mathrm{Si}$ in order to retain an unimplanted region. During implantation, samples were tilted by $\sim 7^{\circ}$ relative to the incident ion beam to avoid channeling.

Postimplantation annealing was carried out in a rapid thermal annealing system in a nitrogen ambient at atmospheric pressure. CL measurements were performed at RT and $\mathrm{LN}_{2}$ using an Oxford Instruments MonoCL2 system installed on a Jeol 35C scanning electron microscope. CL spectra were corrected for system response. Depth-resolved CL measurements have been conducted under the constant beam power condition; i.e., beam energy $\times$ beam current $=$ constant. $^{8}$

Figure 1(a) shows CL spectra obtained at RT from virgin and implanted regions of $\mathrm{GaN}$ bombarded with $150 \mathrm{keV} \mathrm{C}$ ions at $\mathrm{LN}_{2}$ to a dose of $10^{14} \mathrm{~cm}^{-2}$. The spectra illustrate the 


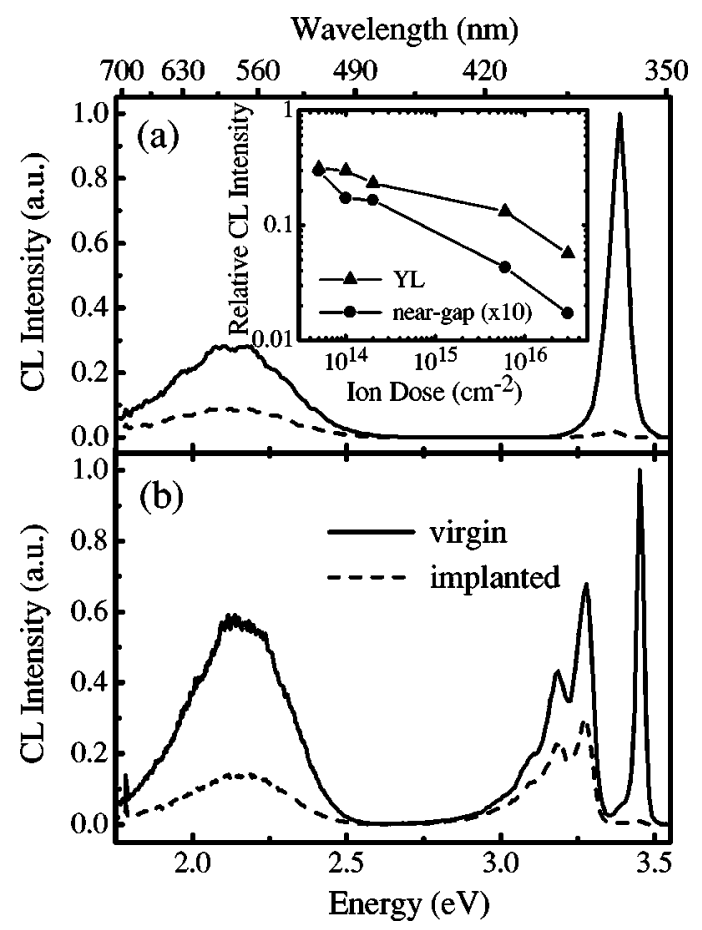

FIG. 1. CL spectra obtained at RT (a) and $\mathrm{LN}_{2}$ (b) from virgin and implanted regions of $\mathrm{GaN}$ bombarded with $150 \mathrm{keV} \mathrm{C}$ ions at $\mathrm{LN}_{2}$ with a beam flux of $3.4 \times 10^{13} \mathrm{~cm}^{-2} \mathrm{~s}^{-1}$ to a dose of $10^{14} \mathrm{~cm}^{-2}$ [electron beam energy $=20 \mathrm{keV}, \mathrm{CL}$ bandpass $=2.5 \mathrm{~nm}$ for (a) and $=1.25 \mathrm{~nm}$ for (b)]. The inset in (a) illustrates the ion dose dependence of the intensities of near-gap and yellow luminescence peaks measured at RT from implanted parts of the samples relative to the corresponding CL intensities in the virgin parts of these samples.

well-known effect of implantation-produced quenching of the intensities of both near-gap emission (centered on $\sim 3.39$ $\mathrm{eV}$ ) and the yellow luminescence (YL) band (a broad defectand/or impurity-related peak centered on $\sim 2.12 \mathrm{eV}$ ) present in this GaN wafer. The inset in Fig. 1(a) shows the ion dose dependence of the intensities of near-gap and YL peaks at RT in implanted parts of samples relative to the corresponding $\mathrm{CL}$ intensities in the virgin parts of these samples. It is seen that, with increasing dose of $150 \mathrm{keV} \mathrm{C}$ ions, the intensities of both near-gap and YL peaks are drastically reduced.

Figure 1(b) shows CL spectra obtained at $\mathrm{LN}_{2}$ from virgin and implanted regions of a GaN sample implanted under the same conditions as the sample shown in Fig. 1(a). The $\mathrm{LN}_{2}$ spectra in Fig. 1(b) consist of near-gap emission at 3.45 $\mathrm{eV}$; donor-acceptor pair emission at $3.28 \mathrm{eV}$ with two longitudinal optical phonon replicas ${ }^{9}$ at 3.18 and $3.08 \mathrm{eV}$, respectively; a broad YL band centered on $2.16 \mathrm{eV}$; and the sharp $\mathrm{Cr}_{\mathrm{Al}}^{0}: \mathrm{Al}_{2} \mathrm{O}_{3}$ emission from the substrate at $1.78 \mathrm{eV}$.

It is seen from Fig. 1(b) that ion implantation considerably reduces the intensities of all CL peaks present at $\mathrm{LN}_{2}$ in the visible part of the spectrum. However, the intensity of near-gap emission is quenched more efficiently than that of the other CL peaks shown in Fig. 1(b). A similar effect can be seen from Fig. 1(a) for the case of RT CL data. Indeed, Fig. 1(a) as well as the inset in this figure shows that ion implantation preferentially reduces the measured intensity of near-gap emission. The depth-resolved CL measurements presented below will provide an explanation for this effect.

Figure 2 shows near-gap and YL depth profiles obtained at R'T from a GaN sample bombarded with $150 \mathrm{keV}$ C ions

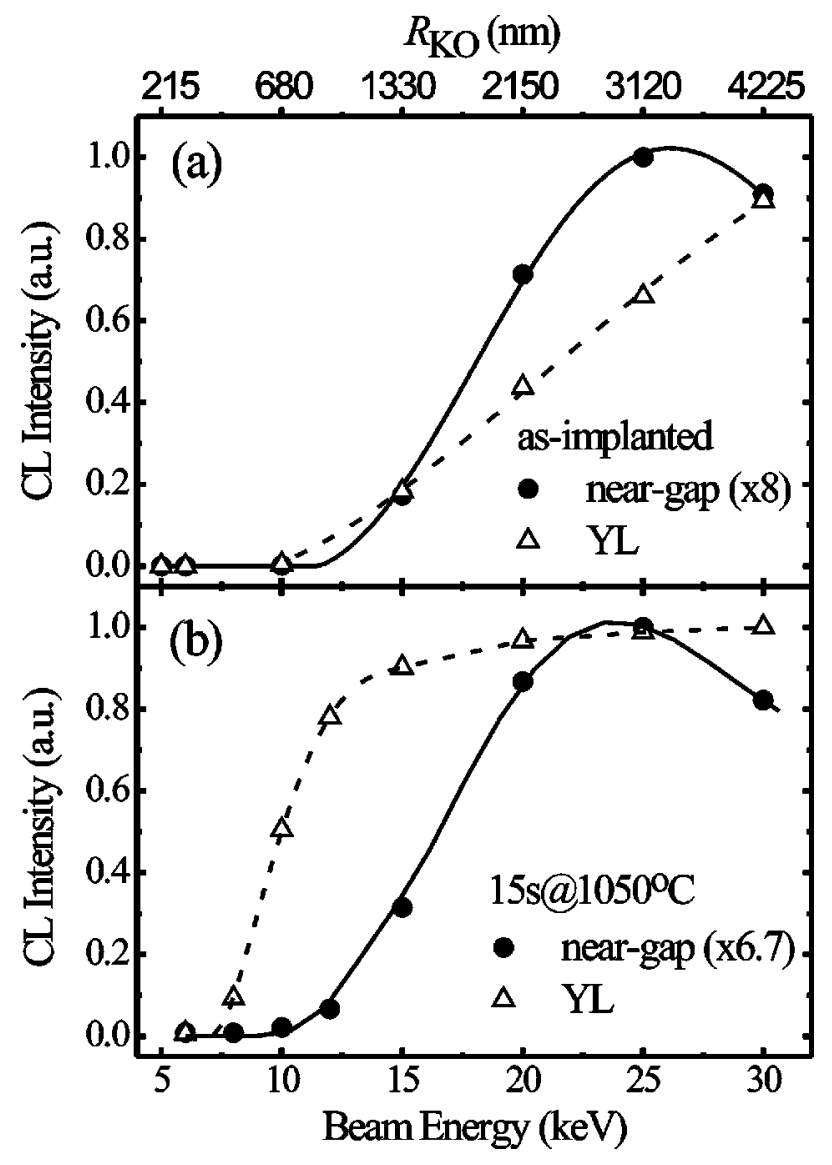

FIG. 2. Near-gap and YL depth profiles obtained at RT from a GaN sample bombarded with $150 \mathrm{keV} \mathrm{C}$ ions at $\mathrm{LN}_{2}$ with a beam flux of 3.4 $\times 10^{13} \mathrm{~cm}^{-2} \mathrm{~s}^{-1}$ to a dose of $5 \times 10^{13} \mathrm{~cm}^{-2}$ (CL bandpass $=25 \mathrm{~nm}$, electron beam power $=7 \mu \mathrm{W}$ ). Shown are the depth profiles of the implanted $\mathrm{GaN}$ sample before (a) and after (b) postimplantation annealing at $1050{ }^{\circ} \mathrm{C}$ for $15 \mathrm{~s}$.

at $\mathrm{LN}_{2}$ to a dose of $5 \times 10^{13} \mathrm{~cm}^{-2}$. In such depth profiles, $\mathrm{CL}$ intensity is plotted as a function of electron beam energy or the corresponding electron penetration range $R_{\mathrm{KO}}$, which can be approximated using the Kanaya-Okayama equation. ${ }^{10}$ For a homogeneous GaN sample, under the conditions of constant beam power employed in this work, the $\mathrm{CL}$ generation rate is essentially constant at different beam energies. ${ }^{11}$

Figure 2(a) shows that, in the ion-damaged layer (up to $\sim 700 \mathrm{~nm}$ from the surface), the intensities of both near-gap and YL peaks are drastically reduced below the detectable level. Therefore, CL emission from the implanted sample shown in Fig. 1, obtained with an electron beam energy of 20 $\mathrm{keV}$, is actually generated by the electron beam impinging on virgin $\mathrm{GaN}$ beyond the implanted layer. ${ }^{12}$ This observation can be used to explain the preferential quenching of near-gap emission compared with the other emission peaks in Fig. 1. Indeed, it has previously been shown ${ }^{8}$ that selfabsorption can change detected CL near-gap emission of asgrown GaN. Our results indicate that implantation-induced absorption of CL in the implanted layer can strongly affect detected near-gap emission from underlying virgin $\mathrm{GaN}$.

As has been reported by several groups (see, for example, Refs. 2-6), the annealing of GaN implanted with $\mathrm{keV}$ ions usually recovers (although always only partly) the measured intensities of light emission. Shown in Fig. 2(b) are CL 
depth profiles taken from the same sample shown in Fig. 2(a) after annealing at $1050{ }^{\circ} \mathrm{C}$ for $15 \mathrm{~s}$. It is seen that such an annealing does not recover either near-gap or YL emission generated in the near-surface region (up to $\sim 450 \mathrm{~nm}$ from the surface). This depth is consistent with TRIM calculations, ${ }^{13}$ which indicate that the layer directly modified by bombardment with $150 \mathrm{keV} \mathrm{C}$ ions (say, $R_{p}+3 \Delta R_{p}$, where $R_{p}$ is the projected ion range, and $\Delta R_{p}$ is the ion straggling) is also $\sim 450 \mathrm{~nm}$ thick. Therefore, the apparent recovery of emission by such an annealing ${ }^{14}$ can be attributed to the thermal recovery of damage that enhances the absorption of light within the implanted layer. This conclusion is consistent with changes in the color of implanted samples observed to result from annealing. ${ }^{15}$ Our results also show that the (partial) recovery of CL emission in the implanted layer by annealing at temperatures up to $1050{ }^{\circ} \mathrm{C}$ occurs only for rather low dose implantation with $150 \mathrm{keV} \mathrm{C}$ ions (doses of $\sim 10^{12} \mathrm{~cm}^{-2}$ ).

Another interesting result from Fig. 2(a) is that, in asimplanted GaN, the CL is quenched up to a depth of $\sim 700$ $\mathrm{mn}$, which is well beyond the layer modified by ion bombardment, as given by TRIM, ${ }^{13}$ which takes into account only collisional processes. Such quenching of CL emission beyond the ion penetration range can be attributed to the diffusion of implantation-produced point defects. This conclusion is supported by the fact that ion-generated point defects are highly mobile in GaN at $\mathrm{LN}_{2}$ and above. ${ }^{16,17}$ Figure 2(b) also shows that the defect complexes formed by such mobile point defects can be effectively removed by annealing at $1050{ }^{\circ} \mathrm{C}$.

Finally, it should be noted that the conclusion that CL of $\mathrm{GaN}$ is dramatically quenched by relatively low dose ion bombardment is consistent with the results of previous luminescence studies of $\mathrm{GaN}$ irradiated with $\mathrm{MeV}$ light ions., ${ }^{76}$ Our analysis of CL spectra from GaN implanted with 150 $\mathrm{keV} \mathrm{C}$ or $1.8 \mathrm{MeV} \mathrm{He}$ ions at RT shows that disorder produced by light-ion bombardment to a critical dose corresponding to the generation of $\sim 5 \times 10^{19}$ vacancies $/ \mathrm{cm}^{3}$ (as estimated using TRIM $^{13}$ ) is sufficient to reduce the intensity of near-gap emission by more than 2 orders of magnitude. However, the exact value of this critical dose depends on a number of implant parameters, such as ion mass, energy, beam flux, and substrate temperature. ${ }^{16}$

In conclusion, the apparent recovery of CL emission from ion-implanted $\mathrm{GaN}$ by post-implantation annealing at temperatures up to $1050{ }^{\circ} \mathrm{C}$ is often caused by changes in the efficiency of the absorption of visible light generated by the electron beam in virgin $\mathrm{GaN}$, beyond the implanted layer.
Thus, CL emission in the implanted layer can remain completely quenched even after such an annealing. Annealing at temperatures up to $1050{ }^{\circ} \mathrm{C}$ can lead to (partial) recovery of CL emission from the layer modified by ion bombardment only for rather low dose light-ion implantation (such as $\sim 10^{12} \mathrm{~cm}^{-2}$ of $150 \mathrm{keV} \mathrm{C}$ ions). The results of this study are important for a correct analysis of the optical doping of $\mathrm{GaN}$ by $\mathrm{keV}$ ion implantation, particularly for heavy ions (such as rare-earth species) when ion-produced lattice disorder is large.

${ }^{1}$ See, for example, recent reviews: S. J. Pearton, J. C. Zolper, R. J. Shul, and F. Ren, J. Appl. Phys. 86, 1 (1999); S. C. Jain, M. Willander, J. Narayan, and R. Van Overstraeten, ibid. 87, 965 (2000), and references therein.

${ }^{2}$ J. I. Pankove and J. A. Hutchby, J. Appl. Phys. 47, 5387 (1976).

${ }^{3}$ E. Silkowski, Y. K. Yeo, R. L. Hengehold, M. A. Khan, T. Lei, K. Evans, and C. Cerny, Mater. Res. Soc. Symp. Proc. 395, 813 (1996).

${ }^{4}$ B. J. Pong, C. J. Pan, Y. C. Teng, G. C. Chi, W.-H. Li, K. C. Lee, and C.-H. Lee, J. Appl. Phys. 83, 5992 (1998).

${ }^{5}$ A. Suvkhanov, J. Hunn, W. Wu, D. Thomson, K. Price, N. Parikh, E. Irene, R. F. Davis, and L. Krasnobaev, Mater. Res. Soc. Symp. Proc. 512, 475 (1998).

${ }^{6}$ C. Ronning, E. P. Carlson, D. B. Thomson, and R. F. Davis, Appl. Phys. Lett. 73, 1622 (1998).

${ }^{7}$ S. O. Kucheyev, J. S. Williams, C. Jagadish, J. Zou, M. Toth, M. R. Phillips, H. H. Tan, G. Li, and S. J. Pearton, Mater. Res. Soc. Symp. Proc. 622, T7.9.1 (2000).

${ }^{8}$ K. Fleischer, M. Toth, M. R. Phillips, J. Zou, G. Li, and S. J. Chua, Appl. Phys. Lett. 74, 1114 (1999).

${ }^{9}$ See, for example, a review by J. W. Orton and C. T. Foxon, Rep. Prog. Phys. 61, 1 (1998).

${ }^{10}$ K. Kanaya and S. Okayama, J. Phys. D 5, 43 (1972).

${ }^{11}$ However, in as-grown GaN, the measured intensity of near-gap emission decreases with increasing electron beam energy due to efficient selfabsorption, and the YL intensity increases with beam energy due to a corresponding increase in the concentration of YL centers towards the GaN/sapphire interface (see, for example, Ref. 8) and/or due to the saturation of YL emission.

${ }^{12}$ Note that the sample shown in Fig. 1 was bombarded to twice the dose $\left(10^{14} \mathrm{~cm}^{-2}\right)$ of the sample shown in Fig. $2\left(5 \times 10^{13} \mathrm{~cm}^{-2}\right)$. Therefore, the effect of the quenching of CL emission coming from the implanted layer is even more pronounced in Fig. 1.

${ }^{13}$ J. P. Biersack and L. G. Haggmark, Nucl. Instrum. Methods 174, 257 (1980)

${ }^{14}$ After such an annealing of the sample from Fig. 2, the relative intensity of near-gap emission (measured with an electron beam energy of $20 \mathrm{keV}$ ) in the implanted part to that in the virgin part of the sample recovered from $\sim 4 \%$ in the as-implanted sample to $\sim 14 \%$ in the annealed one.

${ }^{15} \mathrm{GaN}$ bombarded under implant conditions of this study has a yellowishbrown appearance. The $1050{ }^{\circ} \mathrm{C}$ annealing treatment significantly decreases the efficiency with which visible light is absorbed in the implanted layer, making implanted $\mathrm{GaN}$ appear as transparent as virgin $\mathrm{GaN}$.

${ }^{16}$ S. O. Kucheyev, M. Toth, M. R. Phillips, J. S. Williams, C. Jagadish, and G. Li (unpublished).

${ }^{17}$ S. O. Kucheyev, J. S. Williams, C. Jagadish, J. Zou, and G. Li, Phys. Rev. B 62, 7510 (2000). 